\title{
Effects of Ovulation Stimulating Drugs on the Ultra Structure of Basement Membrane of Luminal Epithelial of Human Endometrial
}

\author{
MH Karimfar ${ }^{1}, \mathrm{P}^{\mathrm{Bazzi}}{ }^{*}$
}

\author{
Article History: \\ Received March 2013 \\ Accepted April 2013 \\ Available online May 2013

\section{Keywords: \\ Basement \\ Membrane,Endometrium \\ Infertility \\ Ovulation stimulating drugs \\ Uterus} \\ Corresponding Author: \\ Bazzi P, Department of \\ Anatomical Sciences, School of \\ Medicines ,Bushehr University of \\ Medical Sciences,Bushehr, Iran \\ Tel: +987712520657 \\ Email: bazzy_par@yahoo.com
}

\begin{abstract}
Objectives: Luminal epithelial basement membrane of endometrial has a major role in implantation. Studies have shown that the rate of successful implantation in stimulatory cycles is less than natural cycles due to detrimental effects of super ovulation drugs on endometrial tissue.The aim of this study is to determine the changes of basement membrane of human endometrial due to the effects of stimulatory drugs.

Material \& Methods: Endometrial tissue samples with natural cycle $(\mathrm{N}=10$, control group), and stimulation cycles $(\mathrm{N}=10$, test group) at the time of implantation $(120 \mathrm{~h}$ after injection of HCG) were prepared. Ovulation was done by injection of agonists GnRH and HMG. The specimens were processed for electron microscopic study. Qualitative study of electron density, and quantitative study increased thickness of basement membrane) were performed on micrograph. The data was analyzed using test.

Results: The qualitative study showed a significant increase of electron density basement membranes in e test group. The quantitative study indicated that some parameter of basement membrane such as overall thickness, dark and clear was significantly increased in test group compared to control group. This difference was statistically significant $(\mathrm{P} \leq 0.05)$.

Conclusion: Considering the above findings, it can be concluded that super ovulation drugs may lead to low implantation rate by affecting the luminal epithelial basement membrane of the endometrium
\end{abstract}

1. Department of Anatomical Sciences, School of Medicine. Zahedan University of Medical Sciences, Zahedan, Iran

2. Department of Anatomical Sciences, School of Medicines, Bushehr University Of Medical Sciences, Bushehr, Iran. 


\section{Introduction:}

Although population control is currently necessary for the overly populated world, but the need to have at least one child has been the desire of mankind since his creation, especially for women. Despite significant advances that have been made with respect to fertility, infertility remains an important issue in society. Many Statistic studies showed that $12 \%$ to $15 \%$ of couples are infertile (1). The causes of infertility include male infertility is $30 \%$, female infertility is $25 \%$, a combination of both male and female factors is $30 \%$, and not described or idiopathic infertility is $15 \%$ ( 2-3-4). One of the important factors in the reproductive process is the role of the endometrium (for receptivity to the blastocyst, implantation, and the fetus development) (5-6). Studies have shown that failure or delay in receptivity and early Implantation are the cause of infertility. Implantation consists of very complex and sensitive cellular and molecular events which require careful coordination of hormones of the hypothalamus, the pituitary and the ovaries and an orchestrated growth and development of the endometrial tissue and the embryo, especially at the time of implantation window (7-8-9-10). Since the implantation takes place in the second half of the menstrual cycle and the endometrial histological changes for the receptivity and blastocyst implantation occur at this stage under the influence of progesterone, It seems that any pathological changes in the endometrium could be due to the changes in the secretion or the early activation of the recipients on the surface of endometrial tissue cells, particularly the luminal epithelial cells (11-12-13-14). Considering the current advances in the field of assisted reproductive techniques of artificial fertilization this has been an important step towards solving the problems of infertility (-15-16-17). Currently, using ovulation stimulating drugs to increase the rate of oocytes obtained per stimulating cycle is routine in most infertility centers (-18-1920). Extensive research on the effects of these drugs on then endometrial tissue has been done. These researches were done on animal models using light microscopes. Researchers found that these drugs may also cause a disturbance of normal cellular and molecular events during the implantation process (21).

The basement membrane plays a very important role in the movement, differentiation, invasion, migration and feeding of the epithelial tissues and, so far, there has been very little research done on its ultra structural changes. Considering the various factors affecting the performance and the fundamental role of the endometrium with respect to receptivity, one of the most consequential factors is the use of ovulation stimulating drugs in stimulated cycles. Therefore, it seems that these drugs have negative effects on luminal epithelial cells and the basement membrane. Therefore in this study possible changes in the basement membrane and its components have been investigated (22).

\section{Material \& Methods:}

Patient selection: In the present study two groups of women were selected for sampling. Control group (Control group $=10$ ): the sampling is taken from women whose reproductivity has been approved and in fact had no problem in terms of fertility. In order to ensure that each group consists of women having no problems in terms of fertility and abnormal lesions, the subjects were selected with the following characteristics:

1 - Not having used any contraceptive methods for at least three consecutive months.

2- Lack of any pathological and abnormal lesions causing intervention in our study.

3- As mentioned in the introduction, age is an infertility risk factor; therefore subjects in this group were 25-35 years old.

4- To assure the fertility of the candidates, women who had given birth to at least one healthy and normal child, were selected.

Case group (10 women): These women due to their infertility had been referred to the infertility center (investigations necessary to ascertain the cause of infertility were done at the center. Studies had shown that the main cause of infertility in these women was the male factor) .Their infertility was 
proven and before being referred to the infertility center for specialized services such as IVF or ICSI, they underwent intrauterine insemination IUI several times hoping to achieve conception, but the result had been negative. These women had no particular problems such as a pathological endometrial, and in this study the male factor was the cause of infertility. The patients underwent protracted treatment of stimulation with Agonists GnRH stimulating Drugs (Buserlin or Super Fact, Dutch company, Organon Dutch ),(subjects received subcutaneous injection to inhibit FSH and LH secretion). After LH, FSH inhibition, IU 300 - 225 of drug HMG (made by the Dutch company, Organon) was injected intramuscularly. This drug induces follicle development and maturation. More oocytes are needed in stimulation cycles. Finally, a single dose of HCG 10000 - 5000 for the final maturation of follicles was injected. Then 34-36 hours after HCG injection, oocytes were harvested through a vacuum pump connected to a needle from transvaginal Ultrasound Probe toward ovary, and oocytes aspirated from the follicles.

\section{Taking Biopsy:}

The patients were treated under IVF or ICSI. If after three days of IVF or ICSI the sperm did not fertilize the egg, or the egg cell did not divide; then, these patients were taken off the treatment protocol and were advised to return three days later when LH +6 was taken to perform the sampling from their uterus fundus with Endometrial Pipelle Section Curette Makk2. Pipelle of samples obtained from the Dutch Rocket International Company.

\section{Tissue preparation:}

For the electron microscopic study, uterine tissue samples of both groups were carefully washed with a solution of sodium phosphate buffer $(\mathrm{PH}=7.2)$ and then specimens were fixed for 5 to 6 hours at a temperature of $4^{\circ} \mathrm{C}$ with glutaraldehyde 2.5 percent solution. After fixation, other preparation steps such as, second fixation in $1 \%$ of Os4 (Tetraoxid Osmium) dehydrated, resin coating, embedding, and modifying templates, making thin and semi-thin sections with ultramicrotome ( $50 \mathrm{Nm}$ ) and finally all specimens were stained with uranil acetate and lead citrate. The photoelecromicrograph were taken step by step with an electron microscope (Philips) and then all the photo micrographs were scanned and saved in the computer and then Image tool Ver.8 software was used to Morph meter for all electro micrographs. To assess qualitative and quantitative changes of basement membrane, the software tool mentioned above was used. Mean thickness in both groups was analyzed, using the statistical T-test. Differences of 0.05 and less than that were considered as significantly.

\section{Results:}

Data and results based on ultra structure morphological characteristics performed with electron microscopy and structures of cells by light microscopy (semi-thin sections) are the qualitative aspects, and morph metric parameters are the quantitative aspects in this study. Therefore, there are two aspects in this study:

A) Morphological aspects (qualitative)

B) Aspects of morph metric (quantitative)

A) Morphological aspects (qualitative)

Figures (1), micrographs of the luminal epithelium of the case and control group respectively at the time of implantation window. As observed luminal epithelium cells are taller and their nucleus are completely euchromatic and the secretions which were not absorbed (arrows head) are visible on the surface of the epithelium, while in the control group, the cells are short and the nucleus is relatively hetero chromic and partial secretions are seen scattered on the surface of the epithelium at the time of implantation window. As it can be seen, the basement membrane of luminal epithelial is more thickness in the case group than control group.

B) Morph metric aspects (quantitative)

In this section, using the Image tool software( Ver.8), basement membrane thickness has been calculated based on the parameters shown in the table1. As noted in the table(1), the basement membrane thickness mean in the case group is 
$258.56 \pm 2.09$ and in the control group is $159.21 \pm$ 1.31.This shows that the difference between these two groups is statistically significant $(\mathrm{P}<0 / 00)$. The average thickness of the clear zone (Electron lucent $=$ Clear zone) in the study group and control group is $81.61 \pm 3.25$ and (53.42 \pm 2.12$)$ respectively. The difference between these two groups is also statistically significant $(\mathrm{p}<0 / 0047)$.The mean thickness of the dark zone (Dark zone $=$ Electron dense) in the case group and the control group is respectively, $176.46 \pm 2.24$ and $105.16 \pm 9.12$ which shows statistically a significant $(p<0 / 000)$.

\section{Discussion:}

Problem of infertility has been an important issue in recent decades. A lot of effort has been put into looking for solutions. Despite the development of medical sciences, especially in the field of infertility, fertilization and implantation remains a major problem. Since the late twentieth century, extensive efforts have been taken to develop a better understanding of issues concerning biology and reproductive endocrinology, especially of the cellular and the molecular events of ovulation, fertilization and implantation. Despite recent advances in the field of artificial fertilization techniques (Assisted Reproductive Technologies = ART), it seems that the infertility problem has only been partly solved; and scientists have come to the conclusion that reproductive science is still facing many problems and are developing techniques of artificial fertilization and techniques of ART because the maximum rate of success in the most advanced fertility centers incorporating these techniques is only $25 \%$. Infertility is an important issue discussed in implantation and fixed embryo implanted. In implantation, the development and interaction of the endometrium and the embryo (blastocyst) is very important. The Uterus is important for the reception and the fixation of the fetus (Receptivity). Receptivity in the uterus for implantation is a complex process in which the ovaries (hormonal) endometrium and the embryo are the constant factors in this phenomenon. It has been determined that the appropriate development of the endometrial for successful implantation of embryos is necessary (23). The second factor in implantation is that, the embryo should be able to respond to the endometrium and produce appropriate connecting molecules (24). This study was conducted in the middle stage of the second half of menstrual cycle (Luteal) (the second half is including three stages: primary, middle and final).

The middle stage of the second half of menstrual cycle is twenty-eight days and it is equal to 22-20 days of regular menstrual cycle. This temporary and limited period of time is an opportunity for the embryo to be able connects to endometrium. This time is known as Implantation window that conforms to the maximum receptivity of uterus (25).

Changes in the basement membrane of the luminal epithelium have been assessed and analyzed into two aspects respectively: (1) morph metric (quantitative) and (2) morphological aspects (qualitative). Therefore, Ultra structural changes of the basement membrane of the luminal epithelial cells in infertile women has been compared with those of fertile women in the middle luteal phase $(\mathrm{LH}+6)$ after receiving ovarian stimulating drugs.

Most research, so far, has been conducted with optical microscopy and only a few Ultra structural studies have been done; therefore, in the present study, changes in endometrial tissue were performed using transmission electron microscopy (TEM) and electronic photomicrograph were used to see the exact structure of endometrial tissue for morph metric (quantitative) and morphological (qualitative) studies. In general, morphological results of the luminal epithelial tissues showed that ovulation stimulating drugs cause developmental progression in the luminal epithelium and increased secretions( forward shift). Due to a lack of fetal development and Synchronization, the process of Opposition (placement) and Attachment (connection) are impeded, and finally uterus receptivity and implantation are reduced. Because the luminal epithelial cells have major role in endometrial 
receptivity for implantation, and increased luminal secretions (due to lack of absorption), over all prevent Opposition and Attachment of blast cyst, it is clear that receptivity of endometrial tissues affected by ovulation stimulating drugs can be reduced. This study was conducted in the luteal middle phase when the luminal epithelial tissues, especially of the basement membrane are undergoing evolutionary changes after receiving ovulation stimulating drugs. In this study the ultra structure of base membrane has been analyzed.

Overall morphological results of electron photo micrographs in the case group compared to the control group (Figures 1) show that in the luminal epithelium tissues, ovulation stimulating drugs taken over a period of time lead to producing increased secretions and a thickening of the basement membranes. Scince these two finding (More secrations and more incease of basal membrane thickness) has negative effect for attachment of embryo to luminal epithelium ,so use of superovulation drugs cause reduction of fertility. These drugs cause disorders in endometrial endocrinology orders and Synchronization, consequently the Opposition and Attachment of the blastocyst is impeded. On the one hand morph metric results obtained from basement membrane parameters (Table 1) show that there is a significant difference in average thickness ratio of the clear zone compared to the dark zone in both the case group and the control group ( $P$ value $<0.05$ ). (significance of basement membrane parameters confirm morphological findings which indicates that the ovulation stimulating drugs increases secretion and thickness of basement membrane, and particularly increases the dark zone thickness which constitutes and act as a physical barrier). Light photo micrographs obtained from semi-thin sections of from morphological point of view shows that luminal epithelium cells are taller and have more secretions on the surface (Figures 1). Taking into consideration, the important role of luminal epithelium cells in endometrial receptivity for implantation; the increase of luminal secretion (due to the lack of receptivity), and thickening of basement membrane (due to high activity of the cells) are over all obstacles, resulting in prevention of Opposition and Attachment of blast cyst. This shows that receptivity of endometrial tissues affected by ovulation stimulating drugs could be reduced. Also, results of other endometrial research (Miosge N. et. al ) in 2005, conducted on mice, showed that the use of stimulating drugs causes changes in the molecular components of basement membrane including the nidogen lamina protein chains, and especially collagen type IV.

\section{Conflict of interest statement:}

We declare that we have no conflict of interest.

\section{Acknowledgments:}

We are thankful to the personnel and management of the electron microscopy department of Veterinary Medicine Faculty, Shiraz University, for their assistance, and also appreciate Research Council, Bushehr University of Medical Sciences for financing this research project. 
Figure1
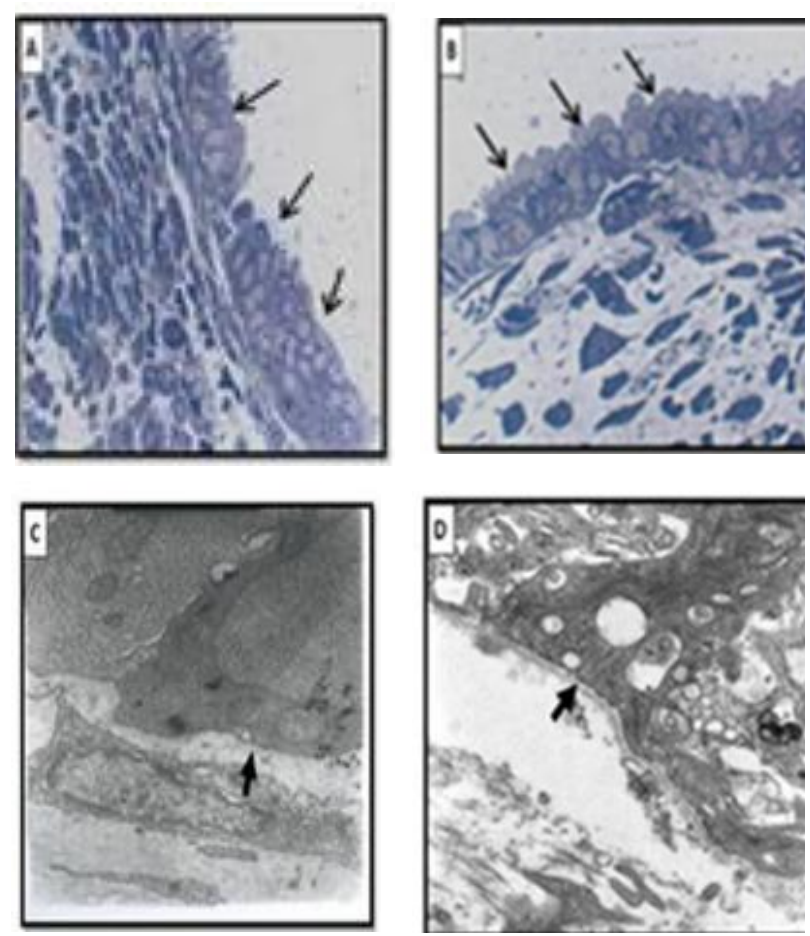

Figure1. Photomicrograph of semi-thin sections of endometrial luminal epithelium in the control (A) and test group (B) at the day of $\mathrm{LH}+6$ $(400 \times)$. Electron micrograph of basement membrane of luminal epithelium in the control(C) and test group (D) at the day of $\mathrm{LH}$ $+6 .(10000 \times)$.
Table 1. The basement membrane thickness of luminal epithelium cells of control and test groups during the implantation window days $(\mathrm{LH}+6)$.

\begin{tabular}{|c|c|c|}
\hline Groups & Control & Test \\
\hline Total-membrane & $159.21 \pm$ & $258.56 \pm$ \\
thickness & 1.31 & $2.09^{*}$ \\
\hline Clear zone & $53.42 \pm$ & $81.61 \pm$ \\
thickness & 2.12 & $3.25^{*}$ \\
\hline Dark zone & $105.16 \pm$ & $176.46 \pm$ \\
thickness & 1.18 & $2.24^{*}$ \\
\hline
\end{tabular}

Data is presented as Mean \pm SD

* Significance rate $(\mathrm{p}<0.05)$ 


\section{References:}

1. Vani K, Kurakula M, Syed R, Alharbi K.Clinical relevance of vitamin C among leadexposed infertile men. Genet Test Mol Biomarkers. 2012; 16(9):1001-6.

2. Kunej T, Zorn B, Peterlin B Y: Micro deletions in fertile men., Ferti Stril. 2003; (3): 1559 65.

3.Klinefelter GR. Anim Reprod Sci. Saga of a sperm fertility biomarker.2008; 105(12):90-103.

4.Aktan G, Doğru-Abbasoğlu S, Küçükgergin C, Kadığlu A, Ozdemirler-Erata G, KoçakToker N. Mystery of idiopathic male infertility: is oxidative stress an actual risk?Fertil Steril. 2013; 99(5):1211-5

5.Haouzi D, Dechaud H, Assou S, De Vos J, Hamamah S. Insights into human endometrial receptivity from transcriptomic and proteomic data.Reprod Biomed Online. 2012; 24(1):23-34.

6. Nikas G: Endometrial receptivity: changes in cell-surface morphology. Semin Reprod Med, 2000; 8(3):229-35..

7.Haouzi D, Dechaud H, Assou S, Monzo C, de Vos J, Hamamah S.Transcriptome analysis reveals dialogues between human trophectoderm and endometrial cells during the implantation period. Hum Reprod. 2011; 26(6):1440-9.

8. Bartosch C, Lopes JM, Beires J, Sousa M.Human endometrium ultrastructure during the implantation window: a new perspective of the epithelium cell types. Reprod Sci. 2011; 18(6):525-39.

9. Hewitt SC, Korach KS.Cell biology. A hand to support the implantation window.Science. 2011; 331(6019):863-4.

10.Sun Q, Xiong J, Liu H.Blank control setting and protein detection method on low-dose aspirin-treated mice during implantation window. Placenta. 2011; (3):292: 293-4.

11. Beato M and Klug J: Steroid hormone receptors, an update. Human Reprod., 2000; (6) 3: $225-236$.

12.Meffre D, Labombarda F, Delespierre B, Chastre A, De Nicola AF, Stein DG, Schumacher M, Guennoun R.Distribution of membrane progesterone receptor alpha in the male mouse and rat brain and its regulation after traumatic brain injury. Neuroscience. 2013; 231:111-24.

13. Apparao k, Chamber BA, Lessey B: Progesterone receptor isoform. B modulates the expression of osteopontin $=$ OPN in human endometrial epithelium during the window of implantation. Ann Meeting Soc. Gynecol. Invest, 2001; 43:60. 
14. Borini A, Tarozzi N, Bizzaro D, Bonu MA, Fava L, Flamigni C, Coticchio G. Sperm DNA fragmentation: paternal effect on early post-implantation embryo development in ART. Hum Reprod. 2006 ; 21(11):2876-81.

15. Lodhi S, Abdel Fattah A, Abozaid T, Murphy J, Formantini E, Sasy M, Barber K, Abuzeid M. Gamete intra-fallopian transfer or intrauterine insemination after controlled ovarian hyper stimulation for treatment of infertility due to endometriosis. Gynecol Endocrinol. 2004; 19(3):152-9.

16 Richings NM, Shaw G, Temple-Smith PD, Renfree MB Intra-cytoplasm sperm injection in a marsupial reproduction. 2004; 128(5):595-605.

17. Badawy A, Baker El Nashar A, El Totongy M. Clomiphene citrate plus N-acetyl cysteine versus clomiphene citrate for augmenting ovulation in the management of unexplained infertility: a randomized double-blind controlled trial. Fertil Sterilv. 2006; 458(2):255-65.

18. Jee BC, Ku SY, Suh CS, Kim KC, Lee WD, Kim SH. Use of letrozole versus clomiphene citrate combined with gonadotropins in intrauterine insemination cycles: a pilot study Fertil Steril. 2006; 85(6):1774-7.

19. Gomes MK, Vieira CS, Moura MD, Manetta LA, Leite SP, Reis RM, Ferriani RA Controlled ovarian stimulation with exclusive FSH followed by stimulation with HCG alone, FSH alone or hMG. Eur J Obstet Gynecol Reprod Biol. 2006; 387(2):157-65.

20.Large MJ, DeMayo FJ.The regulation of embryo implantation and endometrial decidualization by progesterone receptor signaling. . Mol Cell Endocrinol. 2012; 358(2):155-65.

21.Neubauer K, Kruger M, Quondamatteo F, Knittel T, Saile B, Ramadori G.. Transforming growth factor-betal stimulates the synthesis of basement membrane proteins laminar, collagen type IV and entactin in rat liver sinusoidal endothelial cells. J Hepatol. 1999; 31(4):692-702.

22. Santi A, Felser RS, Mueller MD, Wunder DM, McKinnon B, Bersinger NA.Increased endometrial placenta growth factor (PLGF) gene expression in women with successful implantation. Fertil Steril. 2011; 96(3):663-8.

23.Kaneko Y, Day ML, Murphy CR. Uterine epithelial cells: Serving two masters.Int J Biochem Cell Biol. 2012; 45(2):359-363.

24.Chen Q, Zhang Y, Elad D, Jaffa AJ, Cao Y, Ye X, Duan E. Mol Aspects Med. Navigating the site for embryo implantation: Biomechanical and molecular regulation of intrauterine embryo distribution. 2013; 34(5):1024-42.

25. Nikas G: Endometrial receptivity: changes in cell-surface morphology. Semin Reprod Med, 20008; 3:229-35. 